\title{
Electrodeposition of Bi-Sb Alloy Using Cu Electrodes
}

\author{
Masato Ohmukai $^{{ }^{*}}$, Akira Tsuyoshi ${ }^{2}$ \\ ${ }^{1}$ Department of Electrical and Computer Engineering, Akashi College of Technology, Akashi, Japan; ${ }^{2}$ Department of Electrical En- \\ gineering, Kobe City College of Technology, Kobe, Japan. \\ Email: *ohmukai@akashi.ac.jp
}

Received April 24 $4^{\text {th }}, 2012$; revised May 18 ${ }^{\text {th }}, 2012$; accepted June $10^{\text {th }}, 2012$

\begin{abstract}
$\mathrm{Bi}-\mathrm{Sb}$ alloys were grown by means of an electrodeposition method using $\mathrm{Cu}$ electrodes. The alloys were studied with the help of an x-ray diffractometer and an electron probe microanalysis. The both investigations have shown no trace of $\mathrm{Cu}$ in the obtained alloys. It can be concluded that $\mathrm{Cu}$ electrodes can be used for the deposition of Bi-Sb alloys; which results in an advantage of availability of the electrode.
\end{abstract}

Keywords: Electrodeposition; EPMA; XRD; Compound Semiconductors; Thermal Electric Generation

\section{Introduction}

Thermoelectric power generation is attractive from an environment-friendly aspect. Nowadays the solar battery and the wind electric power generation are well accepted and spread out as a clean generation method. For the practical applications of thermoelectric power generation, it is necessary to develop new materials to pursue better effectiveness. At the same time, thermoelectric materials can be applied to electronic cooling and heating devices on the other hand.

Among various materials, $\mathrm{Bi}_{2} \mathrm{Te}_{3}$ has been best known and studied as well as a $\mathrm{Bi}-(\mathrm{Te}, \mathrm{Se})$ alloy. Because of a large thermoelectric figure of merit around $3 \times 10^{-3} \mathrm{~K}^{-1}$ at room temperature [1], the $\mathrm{Bi}_{2} \mathrm{Te}_{3}$ system has been deeply investigated so far. On the basis of its crystal structure, the system shows a large asymmetry in resistivity, Hall coefficient, magnetic resistance and thermal conductivity. Researchers reported the existence of the second conduction band [2,3], the asymmetry of relaxation time of carriers [4], and the determination of the scattering coefficient of carriers [5]. In addition, anisotropic galvanomagnetic and thermoelectric properties have been studied [6]. In recent years several group reported that a superlattice structure enhances thermoelectric figure of merit $[7,8]$. This is actually an excellent idea though forming superlattice requires high-cost manufacturing methods such as a molecular beam epitaxy.

The Bi-Sb alloy is another good candidate for a thermoelectric material in a room temperature range. Further, the Bi-Sb alloy conveniently has the maximum figure of merit at room temperature. V. D. Das et al. reported [9]

*Corresponding author. the dependence of resistance on temperature, in a $\mathrm{Bi}-\mathrm{Sb}$ alloy film deposited by a vacuum deposition method. R. Tolutis et al. [10] observed negative magneto-resistance in a Bi-Sb alloy film. In addition, superlattice nanowire arrays of $\mathrm{Bi}$ and $\mathrm{Sb}$ was recently demonstrated by means of a pulsed electrodeposition method [11]. While the $\mathrm{Bi}-\mathrm{Sb}$ system has been widely studied, a Bi-Sb alloy film was deposited by an electrodeposition method [12]. This method only needs a container of electrolyte, where soaked a substrate and a counter electrode connected with an electric power supply. It is why this method actually has an advantage of low cost for the deposition. An electrode made of $\mathrm{Bi}-\mathrm{Sb}$ alloy has been usually used for the deposition. We tried to use a $\mathrm{Cu}$ electrode for the deposition for the purpose of better availability of the electrode and analyzed the obtained $\mathrm{Bi}-\mathrm{Sb}$ alloy films.

\section{Experimental}

Electrolyte consisted of the mixture of $\mathrm{BiCl}_{3}(12 \mathrm{~g})$ and $\mathrm{SbCl}_{3}(1.5 \mathrm{~g})$ dissolved in aqueous $\mathrm{HCl}(50 \mathrm{ml})$ diluted with water $(100 \mathrm{ml})$. The amount of $\mathrm{SbCl}_{3}$ was quite small because of its hard solubility. A substrate electrode and a counter electrode were situated in the electrolyte at a distance of $1.5 \mathrm{~cm}$ to each other. Both electrodes were made of $\mathrm{Cu}$ plates masked with polymer films where the square $(1 \times 1 \mathrm{~cm})$ area was exposed to the electrolyte. A direct current-constant power supply (40 mA) was connected to the substrate as a cathode and the counter electrode as an anode. The deposition was performed continuously for 20 hours. The voltage appeared across the electrodes was $0.11 \mathrm{~V}$ at the beginning of the deposition.

The amount of the Bi-Sb alloy deposited on the substrate was about $1.8 \mathrm{~g}$. 
The obtained samples were investigated with an X-ray diffraction (XRD) apparatus (RAD-IIA by Rigaku), a scanning electron microscopy (SEM: S-570 by Hitachi) equipped with an electron probe micro analysis (EPMA: EMAX-5770 by Horiba). The main issue of the investigations is elemental constitution of the obtained material.

The surfaces of grown Bi-Sb alloy samples were too rough to measure $\mathrm{x}$-ray diffraction pattern. The grown $\mathrm{Bi}-\mathrm{Sb}$ alloy samples were cleaved off from the $\mathrm{Cu}$ substrate and then the interface to the substrate was analyzed. The grounded powder of Bi-Sb alloy in the surface region is also measured. As for an EPMA measurement, the cross sections of the Bi-Sb alloy samples were studied for a depth profile.

\section{Results and Discussion}

The SEM photos of the cleaved interface and the surface of a BiSb sample are shown in Figures 1(a) and (b), respectively. The obtained BiSb evidently consisted of polycrystals. The grain size at the interface was under 10 $\mu \mathrm{m}$ but that at the surface was several ten $\mu \mathrm{m}$. The fact argues that the crystal grows gradually as the film was deposited thicker.

Figure 2(a) shows an XRD pattern obtained from the cleaved interface of Bi-Sb. Eleven sharp peaks marked with open circles in the figure were observed, corresponding to Bi-Sb were observed, with a small peak situated at 43.5 degree in $2 \theta$ assigned to (111) reflection by $\mathrm{Cu}$. A relatively strong peak at 67.7 degree was not well assigned yet. Figure 2(b) shows a powder XRD pattern from the powder obtained by grinding a part of a surface region only. In this pattern, the same 11 peaks to $\mathrm{Bi}-\mathrm{Sb}$ were observed with a little shift (from 0.2 to 0.4 degree) in the lower side. It can not be determined that the shift derived from the compositional change or the change in stress caused by the grind to powder. It should be mentioned that the structure at 43.5 degree $(\mathrm{Cu})$ was not seen in the Figure 2(b), which argues the reflection by $\mathrm{Cu}$ (111) in Figure 2(a) derived from a $\mathrm{Cu}$ trace that trans-

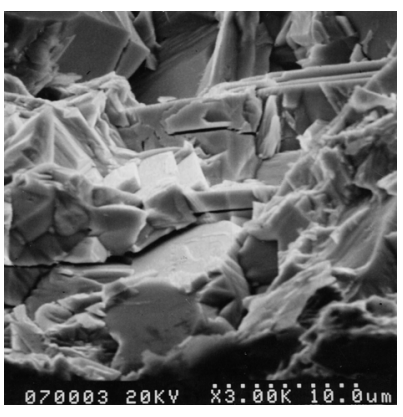

(a)

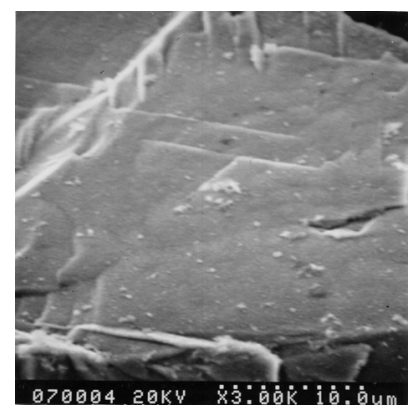

(b)
Figure 1. (a) SEM photograph of electrodeposited BiSb; the cleaved interface contacted to a Cu substrate; (b) SEM photograph of electrodeposited surface of BiSb.

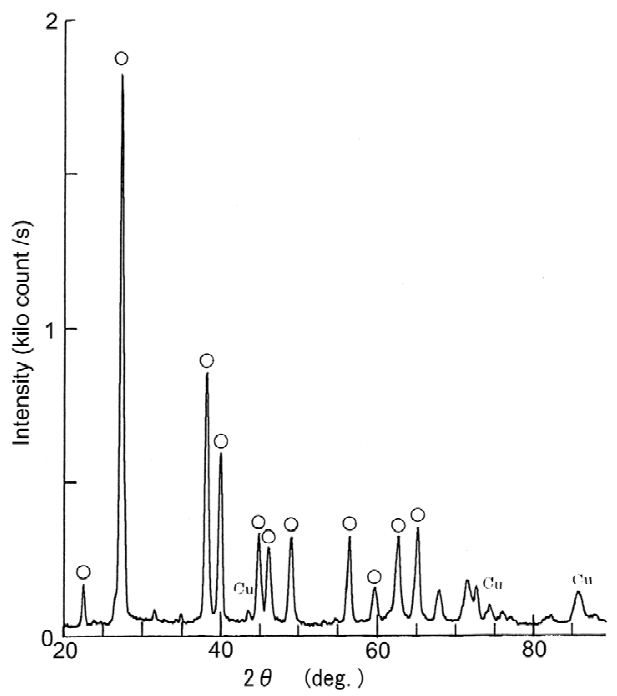

(a)

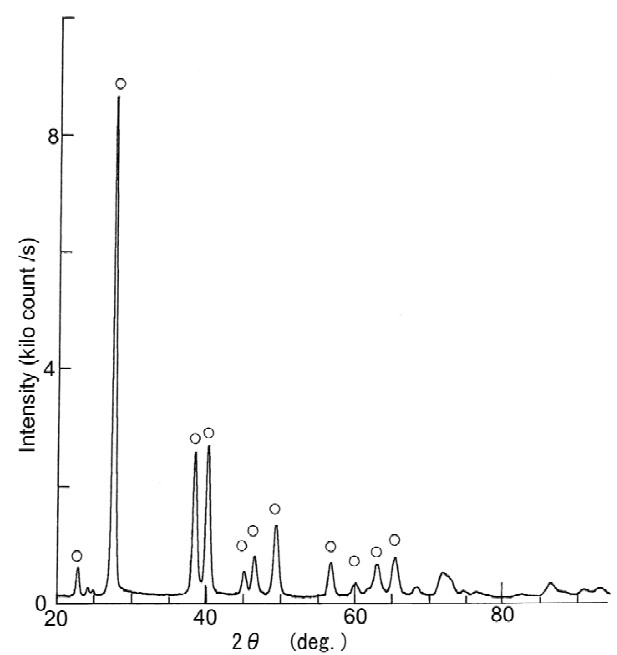

(b)

Figure 2. (a) XRD patterns of obtained BiSb: The cleaved plane; (b) XRD patterns of obtained BiSb: The powdered sample taken from only the surface region.

ferred from the $\mathrm{Cu}$ substrate to the sample when it was cleaved.

In order to determine the compositional ratio, EPMA measurements were performed. The results of linear analyses on a cross sectional plane are shown in Figures 3(a) and (b): the atomic concentration of $\mathrm{Cu}$ and $\mathrm{Sb}$ as a function of the distance from the substrate, respectively.

$\mathrm{Cu}$ was not detected in the grown $\mathrm{Bi}-\mathrm{Sb}$ region at any distance except for $0 \mathrm{~mm}$. The absence for $\mathrm{Cu}$ is consistent with the XRD pattern from the powdered surface region of the grown $\mathrm{Bi}-\mathrm{Sb}$. This means that $\mathrm{Cu}$ was not precipitated even if $\mathrm{Cu}$ was dissolved at the anode. The $\mathrm{Sb}$ atomic concentration was $10 \%$ at the interface and increased to $20 \%$ with the distance. This change probably resulted from the gradual change in solute concentration 

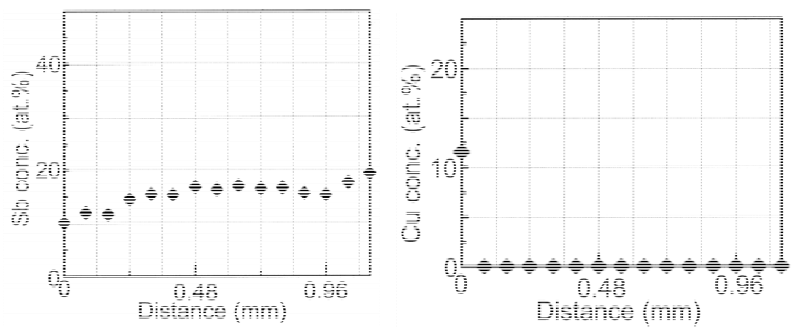

Figures 3. The atomic concentration of $\mathrm{Cu}$ (top) and $\mathrm{Sb}$ (bottom) obtained by means of an EPMA measurement.

in the electrolyte during the growing. The control of concentration in the electrolyte is expected to the precipitation for a constant atomic ratio during the deposition.

It was found that the anode $(\mathrm{Cu})$ was dissolved during the deposition. As a matter of fact the deposited $\mathrm{Bi}-\mathrm{Sb}$ did not include $\mathrm{Cu}$ but the expense of $\mathrm{Cu}$ electrodes is not actually recommended. It is better to use other metal that is not dissolved in the electrolyte for a maintenancefree production method.

\section{Conclusion}

Bi-Sb alloy was electrically deposited in a solution as a low-cost deposition method. When $\mathrm{Cu}$ electrodes were used for the electrodeposition, the obtained $\mathrm{Bi}-\mathrm{Sb}$ alloy film did not contain $\mathrm{Cu}$ on the basis of XRD and EPMA measurements. The atomic concentration of $\mathrm{Sb}$ became larger with the distance from the interface, which was probably originated from the change of solute concentration in the electrolyte.

\section{Acknowledgements}

The authors would like to thank Prof. K. Masui (Nagoya Inst. of Technol.) for fruitful discussion.

\section{REFERENCES}

[1] D. M. Rowe and C. M. Bhandari, "Modern Thermoelectrics," Holt Rinehart and Winston, London, 1983.

[2] R. B. Mallison and J. A. Rayne, "De Haas-Van Alphen Effect in n-Type $\mathrm{Bi}_{2} \mathrm{Te}_{3}$," Physical Review, Vol. 175, No. 3, 1968, pp. 1049-1056. doi:10.1103/PhysRev.175.1049
[3] L. P. Caywood Jr. and G. R. Miller, "Anistropy of the Constant-Energy Surfaces in n-Type $\mathrm{Bi}_{2} \mathrm{Te}_{3}$ and $\mathrm{Bi}_{2} \mathrm{Se}_{3}$ from Galvanomagnetic Coefficients," Physical Review B, Vol. 2, No. 8, 1970, pp. 3209-3220.

[4] M. Stordeur, "Anisotropie des seebeck-koeffizienten, der lorenz-zahl und des hall-koeffizienten von halbleitern, verursacht durch anisotrop gemischte streuung," Physica Status Solidi (b), Vol. 98, No. 1, 1980, pp. 199-206. doi:10.1002/pssb.2220980119

[5] V. A. Kutasov and L. N. Lukyanova, "The Conduction Band Parameters and Scattering Mechanisms in Solid Solutions Based on $\mathrm{Bi}_{2} \mathrm{Te}_{3}$," Physica Status Solidi (b), Vol. 154, No. 2, 1989, pp. 669-677. doi:10.1002/pssb.2221540226

[6] H. Kaibe, Y. Tanaka, M. Sakata and I. Nishida, "Anisotropic Galvanomagnetic and Thermoelectric Properties of n-Type $\mathrm{Bi}_{2} \mathrm{Te}_{3}$ Single Crystal with the Composition of a Useful Thermoelectric Cooling Material," Journal of Physics and Chemistry of Solids, Vol. 50, No. 9, 1989, pp. 945-950. doi:10.1016/0022-3697(89)90045-0

[7] D. Hicks and M. S. Dresselhaus, "Effect of QuantumWell Structures on the Thermoelectric Figure of Merit," Physical Review B, Vol. 47, No. 19, 1993, pp. 12727 12731. doi:10.1103/PhysRevB.47.12727

[8] R. Venkatasubramanian, E. Siivola, T. Colpitts and B. O'Quinn, "Thin-Film Thermoelectric Devices with High Room-Temperature Figures of Merit," Nature, Vol. 413, 2001, pp. 597-602. doi:10.1038/35098012

[9] V. D. Das and N. Meena, "Electrical Properties of $\mathrm{Bi}_{80} \mathrm{Sb}_{20}$ Alloy Thin Films, Vacuum-Deposited at Different Substrate Temperatures," Journal of Materials Science, Vol. 16, No. 12, 1981, pp. 3489-3495. doi:10.1007/BF00586312

[10] R. Tolutis, V. Tolutis, J. Novickij and S. Balevicius, "Negative Magnetoresistance of Polycrystalline Thin $\mathrm{Bi}_{1-x} \mathrm{Sb}_{\mathrm{x}}$ Alloy Films in Quantizing Magnetic Fields," Semiconductor Science and Technology, Vol. 18, No. 6, 2003, pp. 430-433. doi:10.1088/0268-1242/18/6/306

[11] F. H. Xue, G. T. Fei, B. Wu, P. Cui and L. D. Zhang, "Direct Electrodeposition of Highly Dense Bi/Sb Superlattice Nanowire Arrays," Journal of the American Chemical Society, Vol. 127, No. 44, 2005, pp. 15348-15349. doi: $10.1021 / \mathrm{ja} 0547073$

[12] P. M. Vereecken, S. Ren, L. Sun and P. C. Searson, "Electrodeposition of $\mathrm{Bi}_{1-x} \mathrm{Sb}_{\mathrm{x}}$ Thin Films," Journal of the Electrochemical Society, Vol. 150, No. 3, 2003, pp. C131-C139. 